Rochester Institute of Technology

RIT Scholar Works

Articles

Faculty \& Staff Scholarship

$12-2008$

\title{
Optimal Resource Management in the Presence of A Deleterious Alien Species: A Stochastic Model for an Orchard
}

Amitrajeet A. Batabyal

Rochester Institute of Technology

Peter Nijkamp

VU University Amsterdam

Follow this and additional works at: https://scholarworks.rit.edu/article

Recommended Citation

Batabyal, A.A. \& Nijkamp, P. Lett Spat Resour Sci (2008) 1: 107. https://doi.org/10.1007/ s12076-008-0011-7

This Article is brought to you for free and open access by the Faculty \& Staff Scholarship at RIT Scholar Works. It has been accepted for inclusion in Articles by an authorized administrator of RIT Scholar Works. For more information, please contact ritscholarworks@rit.edu. 


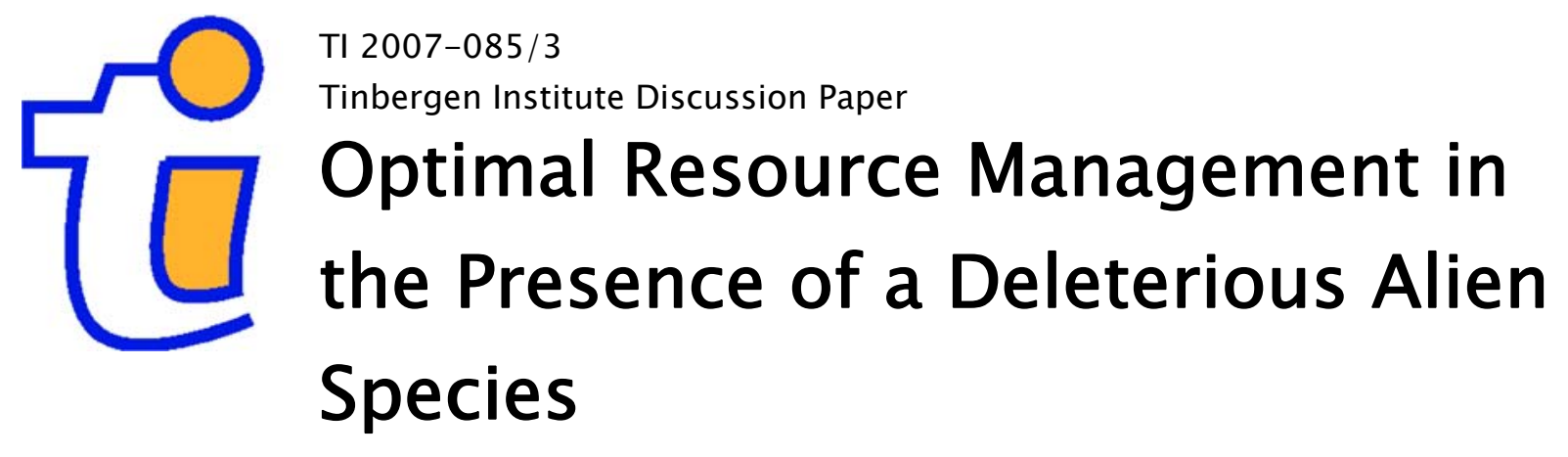

Amitrajeet Batabyal ${ }^{1}$

Peter Nijkamp ${ }^{2}$

' Rochester Institute of Technology,

2 VU University Amsterdam, and Tinbergen Institute; 


\section{Tinbergen Institute}

The Tinbergen Institute is the institute for economic research of the Erasmus Universiteit Rotterdam, Universiteit van Amsterdam, and Vrije Universiteit Amsterdam.

Tinbergen Institute Amsterdam

Roetersstraat 31

1018 WB Amsterdam

The Netherlands

Tel.: $\quad+31(0) 205513500$

Fax: $\quad+31(0) 205513555$

Tinbergen Institute Rotterdam

Burg. Oudlaan 50

3062 PA Rotterdam

The Netherlands

Tel.: $\quad+31(0) 104088900$

Fax: $\quad+31(0) 104089031$

Most TI discussion papers can be downloaded at http:/ /www.tinbergen.nl. 


\title{
Optimal Resource Management in the Presence of a Deleterious Alien Species: A Stochastic Model for an Orchard ${ }^{1}$
}

by

\author{
Amitrajeet A. Batabyal ${ }^{2}$
}

and

Peter Nijkamp ${ }^{3}$

Batabyal acknowledges financial support from the Gosnell endowment at RIT. The usual disclaimer applies.

2

Department of Economics, Rochester Institute of Technology, 92 Lomb Memorial Drive, Rochester, NY 14623-5604, USA. Internet aabgsh@rit.edu

3

Department of Spatial Economics, Free University, De Boelelaan 1105, $1081 \mathrm{HV}$ Amsterdam, The Netherlands. Internet pnijkamp@feweb.vu.nl 


\title{
Optimal Resource Management in the Presence of a Deleterious Alien Species: A Stochastic Model for an Orchard
}

\begin{abstract}
Various plants and resources such as orchards are vulnerable to the detrimental effects of successful invasions by alien animal or plant species. To outline an appropriate policy response, we first use renewal theory to construct a stochastic model of optimal orchard management in the presence of a deleterious alien species. Next, we derive the orchard manager's long run expected cost $(L R E C)$ of orchard management per unit time. Finally, we show that when confronted with a successful biological invasion, the optimal number of trees that need to be removed and replanted in order to keep the orchard under study sustainable in the long run minimizes the $L R E C$ function mentioned above.
\end{abstract}

Keywords: Alien Species, Long Run Expected Cost, Orchard Management, Uncertainty

JEL Codes: Q240, C440 


\section{Introduction}

In an open world, the quality of plants and resources is frequently influenced by complex forces such as the impact of deleterious alien species on vulnerable orchards. The resulting “externality effect” is clearly illustrated in the orchard management problem. In this regard, the reader should note that in contemporary times, all over the world, various kinds of fruits and nuts such as apples, oranges, peaches, and pecans are grown on orchards. As a result, orchards are now key generators of agricultural revenue for their owners and/or managers in disparate parts of the world. Given the work of Batabyal (1999), Batabyal and Yoo (2007a, 2007b), and others, researchers now recognize that the present and the future state of an orchard is defined by factors that are partly economic and partially ecological in nature. The economic factors are rather straightforward. Specifically, orchards are the outcome of human actions that have been taken to promote the commercial and the non-commercial consumption of fruits and nuts. The ecological factors influencing orchards include weeds, inclement weather, and, most notably for our purpose, alien species. Using the parlance of modern researchers, orchards are jointly determined ecologicaleconomic systems. ${ }^{4}$

The extant literature on orchards has analyzed many aspects of their management. For instance, Khushk and Smith (1996) have investigated the consequences of mango orchardists in Sindh, Pakistan, selling their harvesting rights to contractors. Davis et al. (1997) have shown that the unevenness in yields that is commonly encountered in peach production in the United States can be reduced by expanding the distances between peach orchards. Park and Florkowski (2003) have analyzed the impact that orchard conditions and other factors have on the decision to utilize new

Following the work of Perrings (1987), ecological-economic systems are sometimes also known as economy-environment systems. 
varieties in peach production in the United States. Darroch et al. (2004) have studied the effect of alternate investment decisions on the profitability of apple orchard owners in South Africa. Florkowski and Sarmiento (2005) have analyzed the nexus between the prices received by pecan growers and the attributes of their orchards in the United States.

The papers that we have just commented on in the preceding paragraph have certainly increased our comprehension of several aspects of orchard management. Even so, it is important to recognize the following two points. First, orchards are not only jointly determined ecologicaleconomic systems but their growth and output are also dynamic and stochastic in nature. Therefore, sustainable orchard management is fundamentally all about the management of uncertainty over time. Second, as observed by Acquaye et al. (2005) and Pierre et al. (2006), orchards are often invaded by one or more animal or plant alien species. ${ }^{5}$ Hence, effective orchard management ought to take this aspect of the management problem into consideration explicitly. Unfortunately, the papers discussed in the preceding paragraph and indeed the extant literature in general have not satisfactorily accounted for these two points.

Given this state of affairs, our central objective in this paper is to use renewal theory ${ }^{6}$ to construct and analyze a dynamic and stochastic model of optimal orchard management that explicitly takes into account the damage from a successful invasion by an alien animal or plant species. ${ }^{7}$ In this regard, we first derive an orchard manager's long run expected cost (LREC) of

5

Citrus canker and the Mediterranean fruit fly are two examples of alien species that frequently have a negative impact on fruit orchards in Florida in the United States. See Acquaye et al. (2005) and Pierre et al. (2006) for more information on this topic.

6

See Ross (2003, pp. 401-473) and Tijms (2003, pp. 33-79) for textbook treatments of renewal theory.

7

The reader should note that the orchard management problem can also be thought of as a land management problem because an orchard represents a particular kind of land use. 
orchard management per unit time. Next, we focus on the optimal number of trees that need to be removed and replanted to keep the orchard under study sustainable in the long run and we show that this optimal number is the solution to the above mentioned $L R E C$ minimization problem.

The rest of this paper is organized as follows. First, section 2.1 describes the renewal-reward theorem that will form the centerpiece of our orchard manager's $L R E C$ determination problem. Second, section 2.2 derives the $L R E C$ of orchard management per unit time. Third, section 2.3 solves our orchard manager's management problem, i.e., the LREC minimization problem and shows that the optimal number of trees that need to be removed and replanted to keep the orchard under study sustainable in the long run is the solution to this $L R E C$ minimization problem. Finally, section 3 concludes and discusses potential extensions of the research delineated in this paper.

\section{The Theoretical Framework}

\subsection{Preliminaries}

The textbook by Ross (2003, pp. 416-425) tells us that a stochastic process $\{Z(t): t \geq 0\}$ is a counting process if $Z(t)$ represents the total number of counts that have taken place by time $t$. Clearly, since $Z(t-1), Z(t), Z(t+1)$, etc. are stochastic, the time between any two counts $Z(t)$ and $Z(t-1)$ is also stochastic. This time between any two counts is called the interarrival time. A counting process for which the interarrival times have a general cumulative probability distribution function is a renewal process.

Consider a renewal process $\{Z(t): t \geq 0\}$ with interarrival times $X_{z}, z \geq 1$, which have a cumulative probability distribution function $G(\cdot)$. In addition, assume that a monetary reward $R_{z}$ is earned when the $z t h$ renewal is completed. Let $R(t)$, the total reward earned by time $t$, be $\Sigma_{z=1}^{Z(t)} R_{z}$, and let $E\left[R_{z}\right]=E[R]$, and $E\left[X_{z}\right]=E[X]$. The renewal-reward theorem—see Ross (2003, p. 417) or 
Tijms (2003, p. 41) — tells us that if $E[R]$ and $E[X]$ are finite, then with probability one,

$$
\lim _{t \rightarrow \infty} \frac{E[R(t)]}{t}=\frac{E[R]}{E[X]}
$$

In words, equation (1) is telling us that if we think of a cycle being completed every time a renewal occurs, then the long run expected reward — the left-hand-side (LHS) of equation (1) —is the expected reward in a cycle or $E[$ reward per cycle] divided by the expected amount of time it takes to complete that cycle or E[length of cycle]. The reader should note that the renewal-reward theorem holds for positive rewards such as profits and for negative rewards such as costs. Let us now derive the long run expected cost per unit time or $L R E C$ for our orchard manager.

\subsection{LREC of orchard management}

Consider an orchard that consists of $N$ independent, and for all practical purposes, identical, trees that is overseen by a single individual decision maker called the orchard manager. The individual trees in this orchard grow independently of each other. An alien species such as citrus canker or the Mediterranean fruit fly may invade this orchard and if such an invasion does, in fact, occur then we suppose that the trees in our orchard will get infected with a disease at a constant infection rate given by $\mu>0$. Now, consistent with actual practice, ${ }^{8}$ our orchard manager will actually remove the infected trees from the orchard and plant new trees in their place only when the number of infected trees in this orchard reaches the critical number $C$, where $1 \leq C \leq N$.

To reiterate, if the number of infected and diseased trees reaches the critical number $C$ then

8

For more on these matters, go to http://edis.ifas.ufl.edu/CG040 and see, for instance, the 2007 Florida Citrus Pest Management Guide: Citrus Canker. 
our manager simultaneously removes the $C$ infected trees from the orchard and plants new trees in their place. In what follows, to keep the mathematical analysis tractable, we suppose that this simultaneous tree removal and replanting exercise takes a negligible amount of time. Clearly, this tree removal and replanting exercise is costly. As such, we suppose that the total cost of the above exercise is part fixed and part variable in nature. Denote the fixed cost component by $F>0$ and the variable cost component by $\alpha C$, where $\alpha>0$ is the marginal cost of removing and replanting trees. Therefore, in symbols, the total cost of removing and replanting trees is $F+\alpha C$. In addition to the fixed and the variable costs that we have just delineated, we suppose that there is an additional “diseased tree" cost of $\beta>0$ per unit time for each infected and diseased tree in the orchard that is removed by our manager.

Given the above description of the orchard and our orchard manager’s prophylactic activities, the outstanding task before us now is to use the renewal-reward theorem (equation(1)) to derive the $L R E C$ of orchard management. However, before we can use the renewal-reward theorem, we must first specify the apposite renewal process that is the object of our study. In this regard, the reader should note that the continuous time stochastic process describing the number of uninfected or healthy trees is the pertinent renewal process. In addition, the renewal epochs in our model are those time points at which our manager removes the $C$ infected trees from the orchard and plants new trees in their place.

We begin by computing the expected length of the relevant renewal cycle or $E[$ length of cycle]. In this regard, the reader will note that a random variable that is defined to be the minimum of two exponentially distributed random variables with means, say, $1 / \delta_{1}$ and $1 / \delta_{2}$ is 
itself exponentially distributed with mean $1 /\left(\delta_{1}+\delta_{2}\right) \cdot{ }^{9}$ In addition, we know that an exponentially distributed random variable has the memoryless property. ${ }^{10}$ Using these two pieces of information together, we deduce that

$$
\text { E[length of cycle }]=\frac{1}{N \mu}+\frac{1}{(N-1) \mu}+\ldots+\frac{1}{(N-C+1) \mu}=\sum_{i=0}^{i=C-1} \frac{1}{(N-i) \mu} \text {. }
$$

Our next task is to compute the expected cost per renewal cycle or $E$ [cost per cycle]. Our previous specification of the renewal epochs in our model and some thought together tell us that the expectation we seek is given by

$$
E[\text { cost per cycle }]=\frac{\beta}{(N-1) \mu}+\frac{2 \beta}{(N-2) \mu}+\ldots+\frac{(C-1) \beta}{(N-C+1) \mu}=\sum_{i=0}^{i=C-1} \frac{i \beta}{(N-i) \mu}
$$

Having computed the expected cost to the orchard manager in a cycle and the expected length of this cycle, a straightforward application of the renewal-reward theorem — equation (1) — gives us our $L R E C$. Specifically, we get

$$
L R E C=\frac{E[\text { cost per cycle }]}{E[\text { length of cycle }]}=\frac{\sum_{i=0}^{i=C-1} \frac{i \beta}{(N-i) \mu}}{\sum_{i=0}^{i=C-1} \frac{1}{(N-i) \mu}} .
$$

Inspection of equation (4) tells us that our orchard manager's LREC depends fundamentally on the

9

See Taylor and Karlin (1998, pp. 46-47) for more on this basic result.

10

See Ross (2003, pp. 272-275) and Tijms (2003, pp. 440-441) for more on the memoryless property of exponentially distributed random variables. 
number of trees in the orchard $(N)$, the critical number of trees that are infected before prophylactic actions commence $(C)$, the alien species driven tree infection rate $(\mu)$, and finally the cost resulting from the presence of diseased trees in the orchard in a renewal cycle before our manager acts to remove them $(\beta)$. We now use equation (4) and discuss our orchard manager's optimization problem.

\subsection{The optimization problem}

Our orchard manager's objective is to choose the critical number of infected and diseased trees $(C)$ that necessitate his prophylactic tree removal and replanting actions. Mathematically, the optimization problem of interest is ${ }^{11}$

$$
\min _{\{C\}}\left[\sum_{i=0}^{i=C-C-1} \frac{i \beta}{(N-i) \mu}\right] .
$$

After several algebraic steps, the first-order necessary condition for an optimum to this problem can be written as

$$
\left[\sum_{i=0}^{i=C-1} \frac{1}{(N-i) \mu}\right]\left(\frac{\beta}{\mu}\right) \frac{d}{d C}\left\{\frac{C-1}{(N-C+1)}\right\}=\left[\sum_{i=0}^{i=C-1} \frac{i \beta}{(N-i) \mu}\right]\left(\frac{1}{\mu}\right) \frac{d}{d C}\left\{\frac{1}{(N-C+1)}\right\}
$$

Equation (6) tells us that the optimal critical number of trees $C^{*}$ — that must be infected and diseased before our manager takes his prophylactic actions—ought to be chosen in a particular way. Specifically, our manager's optimal choice equalizes the marginal impact of this choice on the

Because the orchard manager's choice variable $C$ is a positive integer, the optimization problem given in equation (5) is, strictly speaking, an integer programming problem. Even so, following the approach employed in Batabyal and Beladi (2006), we use calculus to characterize the optimal solution to this problem. The reader will note that in following this approach, we are implicitly assuming that the optimal integer $C$ can be closely approximated by the optimal continuous $C$. 
weighted expected length of the relevant renewal cycle (the LHS) with the corresponding marginal impact on the weighted expected management cost in this same renewal cycle (the RHS). In order to make additional progress with the optimality condition given in equation (6), one will typically have to make use of numerical methods. This concludes our discussion of the orchard manager's LREC minimization problem.

\section{Conclusions}

In this paper, we used renewal theory to shed light on a simple stochastic model of optimal orchard management in the presence of a detrimental alien species. Specifically, from the standpoint of an orchard manager, we derived the $L R E C$ of management function. We then showed that the critical number of trees in the orchard that must be infected and diseased before the manager takes his prophylactic tree removal and replanting actions is the solution to a particular minimization problem in which the objective function is the above derived $L R E C$ function.

The analysis in this paper can be extended in a number of directions. Here are two suggestions for extending this paper's research. First, following the discussion in section 2.3, it would be useful to conduct numerical analyses to study the nature of the dependence of the $L R E C$ function on the choice of the optimal critical number of trees or $C^{*}$. Second, it would also be useful to eschew the use of the exponential distribution and analyze a model in which the biological invasion driven tree infection and disease rate is variable and not constant. Studies of the optimal management of orchards that incorporate these features of the problem into the analysis will provide additional insights into a management function that has salient economic and ecological ramifications. 


\section{References}

Acquaye, A.K.A., Alston, J.A., Lee, H., and Sumner, D.A. 2005. Economic Consequences of Invasive Species Policies in the Presence of Commodity Programs: Theory and Application to Citrus Canker, Review of Agricultural Economics, 27, 498-504.

Batabyal, A.A. 1999. Aspects of the Optimal Management of Cyclical Ecological-Economic Systems, Ecological Economics, 30, 285-292.

Batabyal, A.A., and Beladi, H. 2006. International Trade and Biological Invasions: A Queuing Theoretic Analysis of the Prevention Problem, European Journal of Operational Research, 170, 758-770.

Batabyal, A.A., and Yoo, S.J. 2007a. A Probabilistic Approach to Optimal Orchard Management, Ecological Economics, 60, 483-486.

Batabyal, A.A., and Yoo, S.J. 2007b. A Stochastic Analysis of the Holling Resilience of an Orchard, Ecological Economics, 64, 1-4.

Darroch, M.A.G., Hardman, P.A., and Ortmann, G.F. 2004. An Assessment of Apple Orchard Investments in South Africa Under Uncertainty and Irreversibility, South African Journal of Economic and Management Sciences, 7, 601-615.

Davis, S.B., Price, J.T., Wetzstein, M.F., and Rieger, M.W. 1997. Reducing Yield Variation in Peach Orchards by Geographic Scattering, American Journal of Agricultural Economics, 79, 1119-1126.

Florkowski, W.J., and Sarmiento, C. 2005. The Examination of Pecan Price Differences Using Spatial Correlation Estimation, Applied Economics, 37, 271-278.

Khushk, A.M., and Smith, L.E.D. 1996. A Preliminary Analysis of the Marketing of Mango in 
Sindh Province, Pakistan, Pakistan Development Review, 35, 241-255.

Park, T.A., and Florkowski, W.J. 2003. Selection of Peach Varieties and the Role of Quality Attributes, Journal of Agricultural and Resource Economics, 28, 138-151.

Perrings, C. 1987. Economy and Environment. Cambridge University Press, Cambridge, UK.

Pierre, R., Spreen, T.H., and Moss, C.B. 2006. Invasive Species and Biosecurity Cost: Cost of Monitoring and Controlling Mediterranean Fruit Flies in Florida, Journal of Agricultural and Applied Economics, 38, 337-343.

Ross, S.M. 2003. Introduction to Probability Models, $8^{\text {th }}$ edition. Academic Press, San Diego, California.

Taylor, H.M., and Karlin, S. 1998. An Introduction to Stochastic Modeling, $3^{\text {rd }}$ edition. Academic Press, San Diego, California.

Tijms, H.C. 2003. A First Course in Stochastic Models. Wiley, Chichester, UK. 